\title{
An Architecture for Wireless Communication Systems using Li-Fi technology
}

\author{
D. Satyanarayana ${ }^{1}$, Alex Roney Mathew ${ }^{2}$, and Sathyashree. $S^{3}$
}

\begin{abstract}
The abundant usage of mobile devices and applications consumes heavy radio spectrum. This has led the current world to use an alternative method of wireless radio communication. Hence, a new technology Light-Fidelity (Li-Fi) has been introduced recently for this purpose. In this paper, we have proposed an architecture which uses Li-Fi technology for communication without having much effort for replacing the existing communication infrastructure. The performance of the proposed architecture is analyzed by carrying out the simulation work consolidating our claim that the use of Li-Fi technology in the data communication increases the data transfer rate.
\end{abstract}

Keywords-Wireless communication, radio spectrum, Li-Fi technology, visible light communication

\section{INTRODUCTION}

$\mathrm{T}$ HE usage of mobile communication devices is increased day by day. In other words, the wireless systems and internet applications are heavily used by people and the bandwidth requirements are increased with the digitization of many non-computer based systems. These bandwidth requirements cause a threat to the world; because the radio frequency bands are predefined for specific applications [1], see the Table 1. The use of one frequency band for another application area is not permitted. One of the best solutions to solve the radio bandwidth problem is to use the cognitive radio networks, where the unused spectrum holes are effectively used. The cognitive radio networks were first introduced in [2][3]. However, due to many reasons such as migration constraints, this method does not solve many problems. In the line of exploring these problems, the researchers have invented a new alternative method for wireless communication using Li-Fi technology [4][5], where the data is transferred through visible light instead of radio. Fortunately, the Li-Fi provides high data rates, which solves many problems of the bandwidth requirements of the modern world. Even though the Li-Fi has high data rates, it has its own

D. Satyanarayana ${ }^{1}$ is with the Department of Electrical and Computer Engineering, University of Buraimi, Al Buraimi, Sultanate of Oman (corresponding author's phone:+968-94793450; email:degala.s@uob.edu.om).

Alex Roney Mathew ${ }^{2}$, is with the Department of Information Technology, College of Applied Sciences, Sohar, Sultanate of Oman. (email:dr.alex.soh@cas.edu.om).

Sathyashree. $S^{3}$ is with the Department of Information Technology, College of Applied Sciences, Sohar, Sultanate of Oman. (email:sathya_degala.soh@cas.edu.om). limitations, and a careful network design is required to get the benefits of it. In other words, replacing the entire existing communication infrastructure and deploying a new one using Li-Fi costs heavy. In this paper, we consider this as a problem and propose a new communication infrastructure which uses the existing heavy public infrastructure and simultaneously attaining the high bandwidth facility using Li-Fi technology. This new architecture uses two levels of communication. At core level, the existing communication infrastructure is used, whereas, at the terminal level the Li-Fi system is used. This type of architecture has many advantages that include low cost, high bandwidth facility. On the other hand, the usage of Li-Fi systems reduces the scarcity of radio spectrum, which is very important in the present communication system.

The next section describes the related work and literature review. The Section III describes the details about the proposed architecture. The Section IV describes the simulation work followed by the conclusion in Section V.

\section{RELATED WORK}

In this section, we present the information related to wireless communication using visible light. Currently, there is a need to find an alternative way for radio communication as

\begin{tabular}{|c|c|c|c|}
\hline \multicolumn{4}{|c|}{$\begin{array}{c}\text { TABLE I } \\
\text { BANDS }\end{array}$} \\
\hline Band & Range & Propagation & Application \\
\hline $\begin{array}{l}\text { VLF(Very Low } \\
\text { Frequency) }\end{array}$ & $3-30 \mathrm{kHz}$ & Ground & $\begin{array}{l}\text { Long-range radio } \\
\text { navigation }\end{array}$ \\
\hline $\begin{array}{l}\text { LF(low } \\
\text { Frequency) }\end{array}$ & $30-300 \mathrm{kHz}$ & Ground & $\begin{array}{l}\text { Radio beacons } \\
\text { and navigational } \\
\text { locators }\end{array}$ \\
\hline $\begin{array}{l}\text { MF(Middle } \\
\text { Frequency) }\end{array}$ & $\begin{array}{l}300 \mathrm{kHz}- \\
3 \mathrm{MHz}\end{array}$ & Sky & AM Radio \\
\hline $\begin{array}{l}\text { HF(High } \\
\text { Frequency) }\end{array}$ & 3-30MHz & Sky & $\begin{array}{l}\text { Citizens band } \\
\text { (CB), ship/aircraft } \\
\text { communication }\end{array}$ \\
\hline $\begin{array}{l}\text { VHF(Very } \\
\text { High } \\
\text { Frequency) }\end{array}$ & $30-300 \mathrm{MHz}$ & $\begin{array}{l}\text { Sky and Light- } \\
\text { of-Sight }\end{array}$ & $\begin{array}{l}\text { VHF TV, FM } \\
\text { Radio }\end{array}$ \\
\hline $\begin{array}{l}\text { UHF(Ultra } \\
\text { High } \\
\text { Frequency) }\end{array}$ & $\begin{array}{l}300 \mathrm{MHz}- \\
3 \mathrm{GHz}\end{array}$ & Light-of-Sight & $\begin{array}{l}\text { UHF TV, cellular } \\
\text { phones, paging, } \\
\text { satellite }\end{array}$ \\
\hline $\begin{array}{l}\text { SHF(Super } \\
\text { High } \\
\text { Frequency) }\end{array}$ & $3-30 \mathrm{GHz}$ & Light-of-Sight & $\begin{array}{l}\text { Satellite } \\
\text { communication }\end{array}$ \\
\hline $\begin{array}{l}\text { EHF(Extremely } \\
\text { High } \\
\text { Frequency) }\end{array}$ & $30-300 \mathrm{GHz}$ & Light-of-Sight & Radar, satellite \\
\hline
\end{tabular}

the radio spectrum is exhausted by the usage of large number 
of internet applications. Moreover, the network speed also decreases with the increase of these applications.

To solve this problem, the researchers have invented wireless communication method using visible light communication (VLC) [6][7]. A researcher Harald et al. described Light Fidelity (Li-Fi) which provides much higher data rates than radio communication [4][5][8][9]. The physical and MAC communication standard for the $\mathrm{Li}-\mathrm{Fi}$ is IEEE 802.15.17[6]. However, there is a lot of work needed to be done at network, transport and application levels.

The Li-Fi architecture contains various devices such as LED bulbs, mobile devices and the photo detector which receives the binary data over light. The binary data is captured by few light receptors which are installed on all types of connecting devices such as computer tablets, phones, televisions, or appliances. The experts say the light pulses are imperceptible to human eye and does not cause any damage or discomfort to eye. The working principle of $\mathrm{Li}-\mathrm{Fi}$ is as follows. There is a LED at one end and the photo detector (light sensor) at another end. The LED is ON if the user wants to send binary one. The similar procedure follows for the binary zero, see the Fig. 1.

The IEEE 802.15.7 standard defines physical layer and MAC layer properties for Li-Fi communications [6]. The standard can provide high data rates useful for audio, video and streaming communication services [7][12][13]. The MAC layer can provide services to TCP/IP protocol at transport and network layers. The physical layer provides three different data rates at different contexts. The PHY I have been made for outdoor communications with the data rate from $11.67 \mathrm{kbps}$ to 267.6 kbps. The PHY II layer allows the communication with $1.25 \mathrm{Mbps}$ to $96 \mathrm{Mbps}$, whereas PHY III is used for high data rates from 12Mbps to $96 \mathrm{Mbps}$.

An efficient method for a downlink of multiuser access in single Li-Fi attocell is described in [23], where the optical AP is located in the ceiling and $\mathrm{k}$ mobile users that are not uniformly scattered within a disc underneath. The spectral efficiency for each user denoted by $T_{k}$ can be found in equation (1).

$T_{k}=\left\{\begin{array}{ll}\log \left(1+\frac{\left(h_{k} a_{k}\right)^{2}}{\sum_{i=k+1}^{k}\left(h_{k} a_{i}\right)^{2}+\frac{1}{p}}\right), & k \neq K \\ \log _{2}\left(1+p\left(h_{k} a_{k}\right)^{2}\right), \quad k=K\end{array}\right\}$

where $h_{1} \leq \ldots . . h_{k} \leq \ldots \ldots . h_{k} . h_{k}$ represents the channel gain of the $\mathrm{K}^{\text {th }}$ user, $a_{k}$ represents the power partition parameter of the $\mathrm{K}^{\text {th }}$ user, $a_{1} \leq \ldots . \leq a_{k} \leq \ldots \ldots . \leq a_{k}$ and $p$ represents the transmit SNR.

The single carrier modulation methods for Li-Fi can be same for wireless infrared communication systems [16]. These methods include On-Off-Keying (OOK), Pulse Position Modulation (PPM) and Pulse Amplitude Modulation (PAM). The PPM method is better in power saving than OOK. A variant of PPM called Variable Pulse Position Modulation (VPPM) [17]. A creative approach for a single carrier and modulation scheme named as Optical Spatial Modulation[18] which is both power efficient and bandwidth efficient for indoor optical wireless communication. To increase the speed

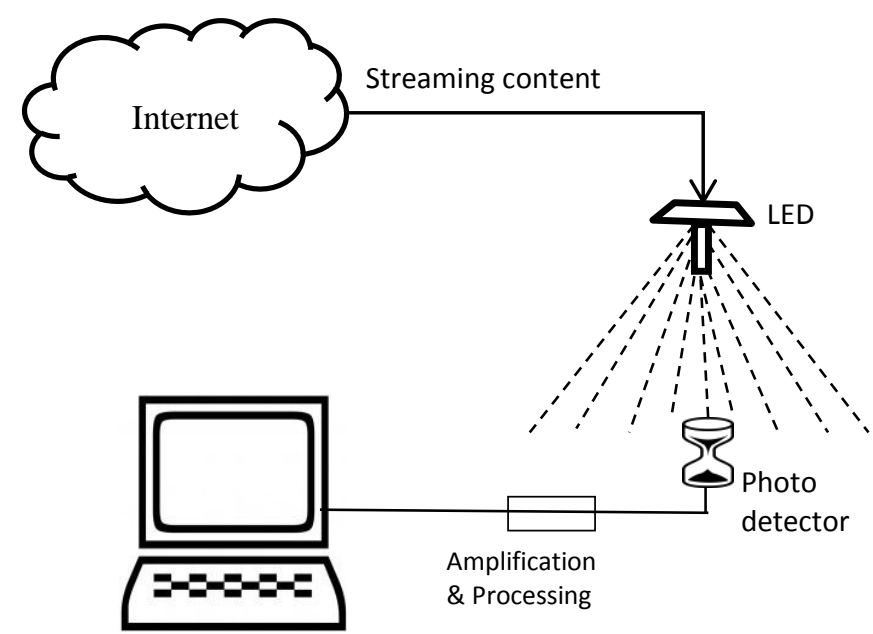

Fig. 1 The binary data transmission using LED and photo detector

of the optical wireless communication, the multicarrier modulation (MCM) is used. The most common MCM scheme is OFDM [19][20], where parallel data streams are transmitted simultaneously. The variations of OFDM are Asynchronous Metrically Clipped Optical OFDM (ACO-OFDM) [21] and Asymmetrically clipped Direct current biasing OFDM (ADOOFDM) [22].

The Maxwell has defined the light propagation phenomena [10]. In other words, the equation (2), (3), (4) and (5) describe how the light signal is converted to electricity. The magnetic and electric fields are constrained to the $z$ and $y$ directions respectively and they both are functions of only $x$ and $t$, see the Fig. 2. From the Maxwell's equation, the wave equations in the free space are

$\nabla \cdot E=0$

$\nabla . B=0$

$\nabla_{x} E=-\frac{\partial B}{\partial t}$

$\nabla_{x} B=\mu_{0} \varepsilon_{0} \frac{\partial B}{\partial t}$

where

$$
\begin{aligned}
& \nabla \text { is the divergence, } \\
& \nabla_{x} \text { is the curl equation, } \\
& \mathrm{E} \text { is Electric field, } \\
& \mathrm{B} \text { is Magnetic field, } \\
& \mu_{0}=4 \pi \times 10^{-7}(\mathrm{H} / \mathrm{m}) \text {, and } \\
& \mathrm{t}_{0}=(1 / 36 \pi) \times 10^{-9}
\end{aligned}
$$

From the above equations, the speed of the light has been derived.

The OLEDCOMM [11] is the first ever commercial product available in the market that uses the Li-Fi technology. In other words, from the LED, the user can listen to music, pay video and easily connect to the internet. It has been showed at the Fudan University that the communication using $\mathrm{Li}-\mathrm{Fi}$ is done at the data rate of $15 \mathrm{Mbps}$ by using few LEDs. However the speed could be increased up to $3.5 \mathrm{Gbps}$. The researchers are actively exploring the different solutions for various problems of the Li-Fi, before the products are arrived to the market. 


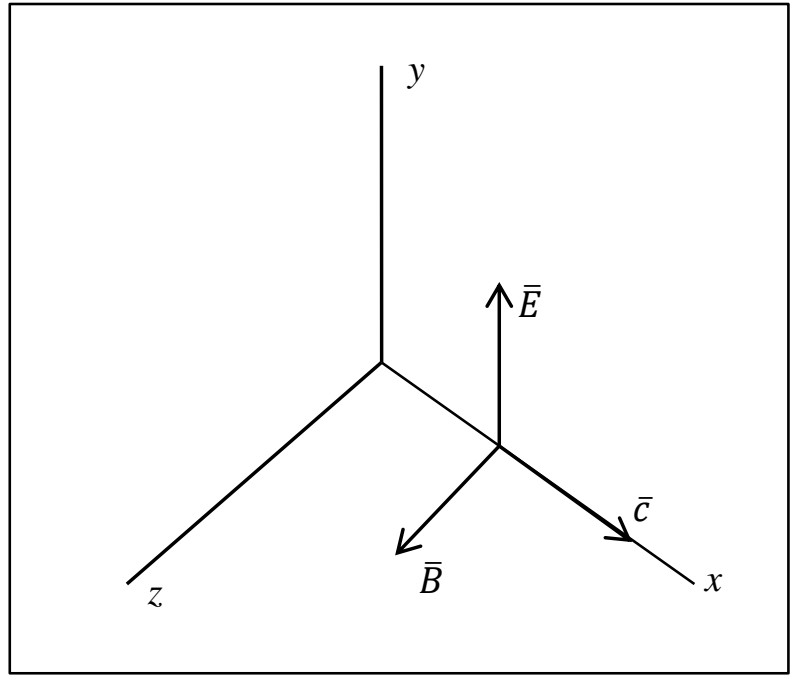

Fig. 2 Electric and Magnetic Fields

\section{The Proposed ARCHITECTURE}

The world is being transformed into digital society where many traditional paper based systems are changed to computer based network systems or internet based systems. In other words, the mobile applications need radio spectrum which is exhausted by the exponential increase of wireless communication users. Note that the radio spectrum bandwidth is predefined, see the Table 1.

\begin{tabular}{|ll|lll|}
\hline \multirow{2}{*}{ Radio wave and Microwave } & Infrared & Light wave \\
\hline 3 & 300 & 400 & 900 \\
$\mathrm{kHz}$ & $\mathrm{MHz}$ & $\mathrm{THz}$ & $\mathrm{THz}$
\end{tabular}

Fig. 3 Electromagnetic spectrum for wireless communication

To solve the radio spectrum problem, one of the alternative solutions is to use the cognitive radio networks [2][3], where the unused spectrum is effectively used by migrating from one frequency band to another frequency band or within the same frequency band. The CRN detects the spectrum holes and allocates them to the CRN users who wait for the channels. However, the CRN does not generate radio spectrum, but the channels are migrated from one band to another band. Another best alternative solution is to use visible light as the communication medium. Please note that the light wave has frequency band from $400 \mathrm{THz}$ to $900 \mathrm{THz}$, which is not preallocated, see the Fig. 3. The Li-Fi uses visible light communication (VLC) technology rather than using radio spectrum [4][5][8][9]. However, in cities the backbone network is well established and it is difficult to replace the entire infrastructure by Li-Fi systems. In other words, the Li-Fi has its own limitation such as the Li-Fi uses Line-of-sight propagation model and the light wave into objects such as building walls. Hence, a careful design of communication infrastructure is required using Li-Fi technology. In this paper, we propose an architecture which uses two levels of communication. In the level 1, Li-Fi is used for communication and in level 2, the existing public infrastructure is used for communication.
The house and the building communication are done though the Li-Fi and the outside communication is maintained with the existing communication infrastructure. Each building has a Li-Fi access point (AP) which converts the light signals to radio signals or electrical signals. These Li-Fi access point (AP) connect to the existing public network. On the other hand, the mobile devices in the home or office are connected to Li-Fi AP through either point-to-point communication or through relay devices. The building communication system is created using Li-Fi technology. However, as the light does not penetrate the walls or hard objects, the light signals need to be reached to the mobile devices in multiple hops using relay devices. For example, in one house, the light signal can be transmitted to different mobile devices/computers either in a single hop or in multiple hops, see the Fig. 4.

The Li-Fi AP's are connected to the traditional backbone network by using either radio or wired networks, see the Fig. 5. We assume that the AP has a special hardware to convert the light signals to either radio signals or electrical signals. The proposed architecture assumes that Li-Fi uses DAC based LED transmitter. The chip has four separate device channels [14]. Each channel is capable of driving up to two LEDs allowing CSK with multiple input and multiple output (MIMO) systems. In addition, on the receiving end, an avalanche photo detector (APD) based receiver is placed. The Li-Fi receiver chip composed of 49 APD detectors based on $180 \mu \mathrm{m}$ CMOS technology [15]. The public network may be fiber optical network or radio wireless network or wired network or the mixture of them. In addition, we assume that the relay/amplifier devices are available. This kind of architecture has many advantages. The data rate of the network is high for this kind of architectures as the data rate of Li-Fi is much higher than radio communication [7][12].

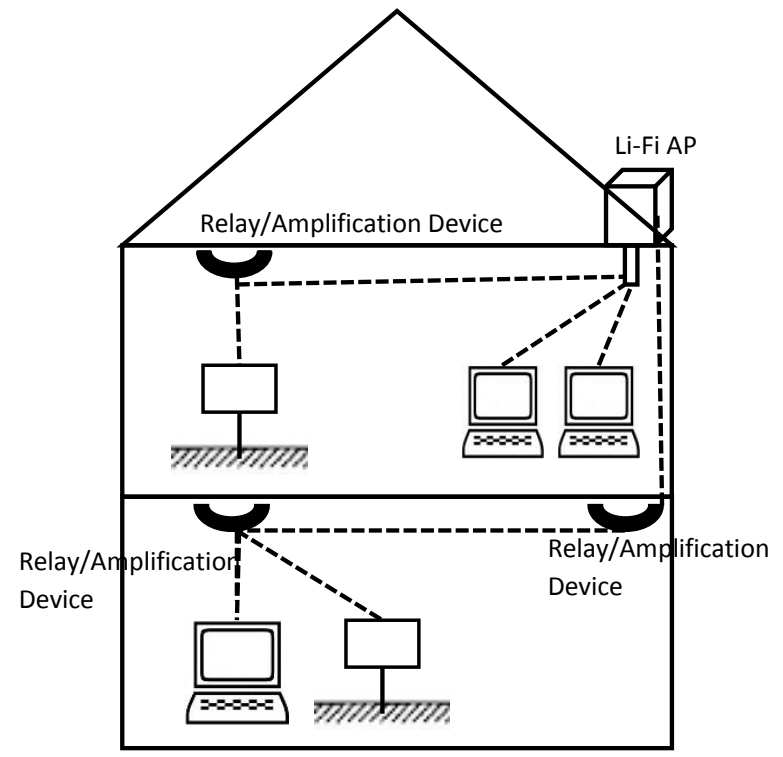

Fig. 4 Data Communication between Li-Fi AP and mobile devices. 


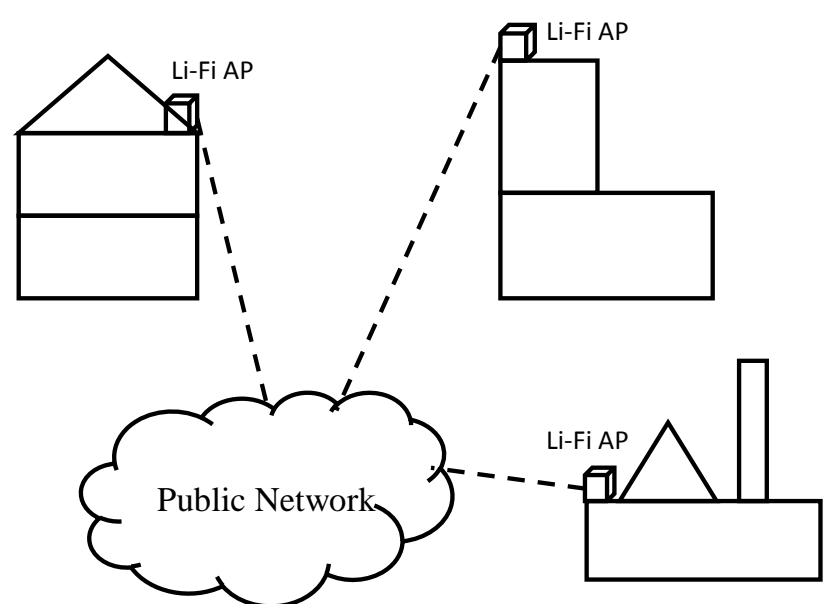

Fig. 5 Data Communication between Li-Fi APs and Public network

The second advantage of using this architecture is that the large number of radio channels can be saved because of the number of wireless applications or the use of wireless devices are more in homes and offices. The third advantage is the adaptability, that is deploying the Li-Fi communication system in home is easy. However, replacing building communication system by Li-Fi takes considerably less effort compared to the effort of replacing public network.

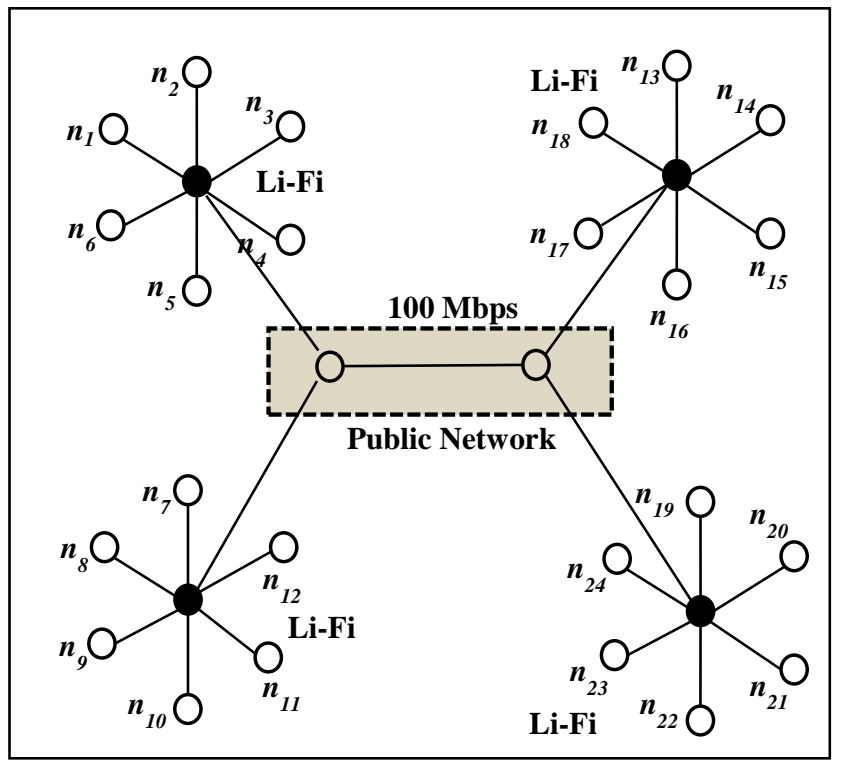

Fig. 6 Network Topology for simulation

\section{Simulation}

The simulation work uses the network topology as shown in Fig. 6. In this topology, it uses Li-Fi communication system for communication at the terminal area and the public network exists in between these end points. The data transfer rate for the $\mathrm{Li}-\mathrm{Fi}$ is taken as $3 \mathrm{Gbps}$ and the public networks as $100 \mathrm{Mbps}$. For the purpose of comparison, we have taken the same network topology and data transfer rates except that the $\mathrm{Li}-\mathrm{Fi}$ is replaced with WLAN (IEEE 802.11b) for which the data rate is $11 \mathrm{Mbps}$.
We have done the simulation by sending the data from ten randomly chosen nodes with the data rates of $2,4,6,8,10,12$, $14,16,18$, and 20Mbps. We have calculated the end-to-end packet delay for the two network topologies where one has Li$\mathrm{Fi}$ and the other has $802.11 \mathrm{~b}$ WLAN. The graph has been plotted for the delay, see the Fig. 7. The results show that the delay for Li-Fi based topology is significantly less compared to the WLAN based topology. This could happen because the data transfer rate for Li-Fi is much higher than the data rate of WLAN.

\section{CONCLUSION}

The radio spectrum is exhausted due to the heavy usage of wireless applications and there is a need for an alternative of wireless communication. The Li-Fi is a visible light communication technology which can provide high data rates to satisfy the current needs. In this paper, we have proposed a new architecture which is suitable to the current systems without many modifications in the existing communication infrastructure. The simulation work shows that the data rates are much improved in case the Li-Fi is used in the network.

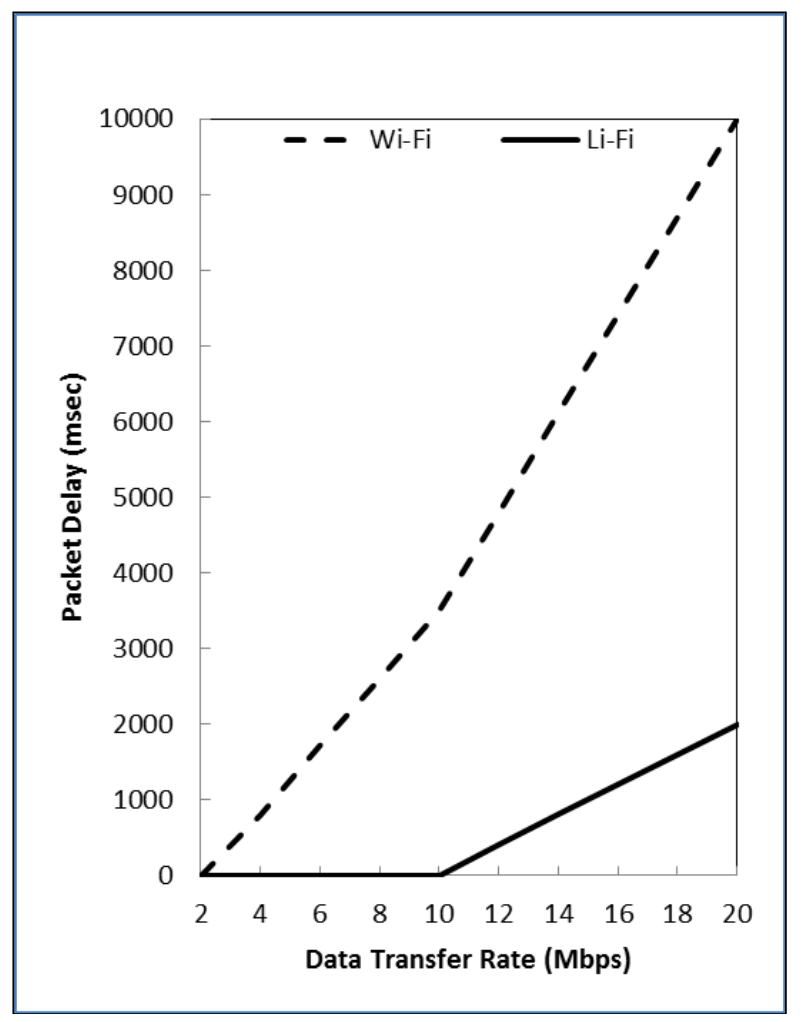

Fig. 7 Packet delay of Li-Fi and Wi-Fi

\section{REFERENCES}

[1] Behrouz A. Forouzan, Data Communications and Networking, Fourth Edition, The McGraw-Hill Companies, Inc, 2007.

[2] J. Mitola III and G. Maguire Jr, "Cognitive radio: making software radios more personal," Personal Communications, IEEE, vol. 6, no. 4, pp. $13-18,1999$.

http://dx.doi.org/10.1109/98.788210

[3] J. I. Mitola, "Cognitive Radio: An Integrated Agent Architecture for Software Defined Radio Dissertation," Dissertation Royal Institute of Technology Sweden, vol. 294, no. 3, pp. 66-73, 2000. 
[4] S. Dimitrov and H. Haas, Principles of LED Light Communications: Towards Networked Li-Fi, 2015, Cambridge Univ. Press http://dx.doi.org/10.1017/CBO9781107278929

[5] H. Haas, "Wireless data from every light bulb", TED Website[Online]. 2011 Available: http://bit.ly/tedvlc

[6] S. Rajagopal, R. Roberts and S.-K. Lim, "IEEE 802.15.7 visible light communication: Modulation schemes and dimming support", IEEE Commun. Mag., vol. 50, no. 3, pp. 72-82, 2012 http://dx.doi.org/10.1109/MCOM.2012.6163585

[7] Khalid, A. M., Cossu, G., Corsini, R., Choudhury, P., and Ciaramella, E., "1-Gb/s Transmission Over a Phosphorescent White LED by Using Rate-Adaptive Discrete Multitone Modulation," IEEE Photonics Journal 4, 1465-1473 (Oct. 2012). http://dx.doi.org/10.1109/JPHOT.2012.2210397

[8] H. Haas and C. Chen "What is LiFi" in Proc, 41st European conference on Opt Communication, Valencia, Spain, Sept,27,2015, pp:1-3, doi: 10.1109/ECOC.2015.7341879 http://dx.doi.org/10.1109/ECOC.2015.7341879

[9] Dobroslav Tsonev, Stefan Videv, Harald Haas, Light fidelity (Li-Fi): towards all-optical networking in Proc. SPIE 9007, Broadband Access Communication Technologies VIII, 900702 (December 18, 2013); doi: $10.1117 / 12.2044649$. http://dx.doi.org/10.1117/12.2044649

[10] S. J. Orfanidis, Electromagnetic Waves and Antennas, online book, 2004-2010

[11] http://www.oledcomm.com/home/parallax/01-parallax

[12] Cossu, G., Khalid, A. M., Choudhury, P., Corsini, R., and Ciaramella, E., "3.4 Gbit/s Visible Optical Wireless Transmission Based on RGB LED," Optics Express 20, B501-B506 (2012). http://dx.doi.org/10.1364/OE.20.00B501

[13] Azhar, A., Tran, T., and O'Brien, D., "A Gigabit/s Indoor Wireless Transmission Using MIMO-OFDMVisible-Light Communications," IEEE Photonics Technology Letters 25, 171-174 (Jan.15 2013). http://dx.doi.org/10.1109/LPT.2012.2231857

[14] Z. Chen, D. Tsonev and H. Haas, "A novel double-source cell configuration for indoor optical attocell networks", Global Telecommunication Conf.Austin,TX,USA, Dec.8-12,2014 http://dx.doi.org/10.1109/glocom.2014.7037122

[15] S. Rajbhandari, H. Chun, G. Faulkner, K. Cameron, A. V. N. Jalajakumari, R. Henderson, D. Tsonev, M. Ijaz, Z. Chen, H. Haas, E. Xie, J. J. D. McKendry, J. Herrnsdorf, E. Gu, M. D. Dawson and D. O’Brien, "High-speed integrated visible light communication system: Device constraints and design considerations", IEEE J. Sel. Areas Commun., vol. 33, no. 9, pp. 1750-1757, 2015. http://dx.doi.org/10.1109/JSAC.2015.2432551

[16] J. M. Kahn and J. R. Barry, "Wireless infrared communications", Proc. IEEE, vol. 85, no. 2, pp. 265-298, 1997 http://dx.doi.org/10.1109/5.554222

[17] IEEE Std. 802.15.7-2011, 2011, IEEE Standard for Local and Metropolitan Area Network, Part 15.7: Short-Range Wireless Optical Communication Using Visible Light, IEEE Std.,2011.

[18] R. Mesleh, H. Elgala and H. Haas, "Optical spatial modulation", IEEE/OSA J. Opt. Commun. Netw., vol. 3, no. 3, pp. 234-244, 2011 http://dx.doi.org/10.1364/JOCN.3.000234

[19] T. Komine, S. Haruyama and M. Nakagawa, "Performance evaluation of narrowband OFDM on integrated system of power line communication and visible light wireless communication", Proc. Int. Symp. Wireless Pervasive Comput., 2006 http://dx.doi.org/10.1109/iswpc.2006.1613633

[20] M. Z. Afgani, H. Haas, H. Elgala and D. Knipp, "Visible light communication using OFDM", Proc. 2nd Int. Conf. Testbeds Res. Infrastruct. Develop. Netw. Commun., pp. 134, 2006 http://dx.doi.org/10.1109/tridnt.2006.1649137

[21] J. Armstrong and A. Lowery, "Power efficient optical OFDM", Electron. Lett., vol. 42, no. 6, pp. 370-372, 2006 http://dx.doi.org/10.1049/el:20063636

[22] S. Dissanayake, K. Panta and J. Armstrong, "A novel technique to simultaneously transmit ACO-OFDM and DCO-OFDM in IM/DD systems", Proc. IEEE GLOBECOM Workshops, pp. 782-786, 2011 http://dx.doi.org/10.1109/glocomw.2011.6162561

[23] Y. Saito, Y. Kishiyama, A. Benjebbour, T. Nakamura, A. Li and K. Higuchi, "Non-orthogonal multiple access (NOMA) for cellular future radio access", Proc. IEEE Veh. Technol. Conf., pp. 1-5, 2013 http://dx.doi.org/10.1109/vtcspring.2013.6692652 